\title{
Innovative Teaching Technologies as a Way to Increase Students' Competitiveness
}

\author{
O. M. Galynska ${ }^{1}$, N. V. Shkoliar ${ }^{2}$, Z. I. Dziubata ${ }^{3}$, S. V. Kravets ${ }^{4}$, N. S. Levchyk ${ }^{4}$ \\ ${ }^{1}$ National University of Food Technologies, 68, Volodymyrska Str., 01601, Kyiv, Ukraine \\ ${ }^{2}$ Khmelnytskyi National University, 11, Instytuts'ka Str., Khmelnytskyi, 29016, Ukraine \\ ${ }^{3}$ Separated Subdivision of National University of Life and Environmental Sciences of Ukraine \\ "BerezhanyAgrotechnical Institute", 20, Akademichna Str., Berezhany, 47501, Ukraine \\ ${ }^{4}$ Ternopil Volodymyr Hnatiuk National Pedagogical University, 2, M. Kryvonosa Str., Ternopil, \\ 46027, Ukraine
}

Received: July 29, 2021. Revised: August 23, 2021. Accepted: August 25, 2021.

Published: August 27, 2021.

\begin{abstract}
The article presents an analysis of innovative teaching technologies as a way to increase students' competitiveness. The author found that innovative technologies in education are information and communication technologies relying on computer-based learning. The structure, content of educational software, organization of Web-space are important when using innovative teaching technologies in English classes. We conducted the study in several stages: comparative analysis, synthesis, classification and systematization of the results of psychological and pedagogical, educational and methodological research; study of legislative acts, periodicals in order to identify the state of the research issue, and determining the directions of its solution, as well as subject, goal and objectives of the study. We used modelling to create situations of foreign language professional communication of future IT specialists. Empirical methods involved questionnaires used for identifying the motives of professional development and determining the features of the educational activities of future IT specialists in the process of training. The methods of mathematical statistics allowed to scientifically describe and systematize the obtained data, to identify the quantitative relationship between the studied phenomena, to analyse and summarize the results. We conducted a socio-psychological study during 2016 - 2019. It involved 255 first- and fourth-year students of National Technical University of Ukraine "Igor Sikorsky Kyiv Polytechnic Institute." Innovative information and communication technologies that improve the educational and cognitive activity of students, as well as increase the level of their
\end{abstract}

knowledge have become important in teaching a foreign language in higher educational institutions. These technologies include MOODLE - Modular ObjectOriented Dynamic Learning Environment, business game, integrated pedagogical technology, case study technology. Thus, the information-rich learning process in combination with the use of innovative technologies, wellorganized e-learning, interactive training courses, multimedia tools improves the program of teaching and learning foreign languages in general, and English in particular, improves the level of knowledge of future IT specialists and motivation to study and learn foreign languages, allows students to use a variety of authentic materials. We state that all these factors influence the process of individualization of learning and contribute to the successful mastery of a foreign language.

Keywords-Innovative teaching technologies, IT specialist, information and communication technologies, business game technology, case study technology.

\section{INTRODUCTION}

\section{A. Research topicality}

Today, innovative technologies act as an innovation aimed at improving efficiency in the educational process. The introduction of innovative technologies in the pedagogical practice of teaching students is necessary for the development of professional competencies of the future specialist. When preparing students for teachers of higher education in conducting classes in disciplines should be developed an individual approach to each of the students, applied practical and theoretical basis. 
Professional competencies in the use of innovative teaching methods must be used in accordance with the requirements set out in the curriculum. With the advent of new technologies, it is increasingly difficult to interest modern students with the help of standard lectures, so the teacher needs to be smart and develop innovative technologies that fit his subject. When using innovative technologies, higher education involves improving the methodology of teaching disciplines, using an approach that realizes the creative potential of the student. It is necessary to combine two competencies in the preparation of students: intellectual and practical activities. In this regard, an important component in pedagogical practice is practical training, which involves the technical implementation of projects.

The important tasks of teaching in the process of teaching bachelors and masters are to apply knowledge in the field of computer technology. In the process of professional training of students, an integral part is research work, which is organically inherent in educational and creative activities. The application of research activities in the process of higher education is due to the problem of mastering the culture of scientific research, as well as scientific and practical skills.

Development of integration processes, conclusion of international contracts, agreements, development of professional and cultural relations of Ukraine with other foreign countries, as well as increasing volume of information requires the future teacher of the higher educational institution (HEI) to have knowledge of a foreign language at the level of no less than B2 (independent user), which com-plies with modern European standards. Therefore, we currently need to develop new approaches to the implementation of innovative technologies of teaching foreign languages in order to train competitive specialists who are able to communicate freely in a foreign language and perform all professional tasks.

A foreign language differs from other subjects in the fact that it is a branch of knowledge because it informs future specialists about a foreign culture and a new lifestyle.

The National Doctrine of Education Development of Ukraine in the XXI century, the Law of Ukraine "On Education", and the Law of Ukraine "On Higher Edu-cation" guide researchers and teachers in the professional training of modern qualified specialists.

In addition, to use a foreign language in future professional activities, it is necessary to find ways and methods to improve learning in classes of foreign languages as a means of communication. This process aims at developing mobility and competitiveness in students, promotes a high level of professionalism, develops communicative competence for the realization of interaction during professional activities.

In the modern world, methods of teaching foreign languages in HEIs should be better adapted to the ever-changing needs and conditions of language learners. The use of new technologies during the lesson helps to increase the individualization of learning. Many issues related to the use of innovative teaching technologies remain unresolved, as they require detailed study, focusing on the specifics of professional training in different specialties.

Globalization processes in education contributed to the development and implementation of new curricula, methods and technologies for training future specialists. English has become international and is used in literary creative work [1], [2]. As the world has become more mobile, learning approaches changed. Thus, language learning is realized through the use of mobile devices [3].

\section{B. Review of recent research and publications}

The problem of innovative technologies of teaching English language to im-prove the foreign language training of future specialists in HEIs was studied by domestic and foreign scholars, as well as specialists who use Internet technologies in teaching English. Scholars, namely: Bezpalko, Bracamonte, Brucher, Dun-kel, Simonson substantiated the problem of development of intercultural communicative competence of students in HEIs.

Problems of academic attractiveness of higher education in Ukraine are considered in the work [4]. The authors also consider the issues of competitiveness and sources of funding for higher education in Ukraine.

Nisimchuk, Tsyrkun, Richardwards studied the role and place of modern technologies in the process of training, the use of innovative communication and information technologies in the development of competencies of future world-class specialists. Gosteva, Ivanova examined online learning and Internet re-sources in their research.

The foreign scholar Thomson notes in his research that teachers and students focus more on a content of the course in the learning process. It is online learning that contributes to the fact that students can independently determine the time and area that corresponds to their learning activities. According to the scholar, online courses allow students choosing a convenient place and time. Even those students who have a low level of knowledge can better understand the material when listening to video lectures again. These courses, help to conduct accelerated professional training, for example, in professional development [5]. As you know, teachers and students can choose online learning based on their enthusiasm in order to improve their technical skills. Due to the increasing role and number of online projects and courses, there is a need to clearly organize and implement learning conditions for improving students' competence [6].

Besides, as [7] note, effective learning activities require developing students' motivation to achieve the main objectives during professional training.

Students who have a high level of motivation to study have high scores on online courses. Researchers in this field often compare online courses in experimental or quasi-experimental studies [8].

The research objective is the study of innovative teaching technologies as a way to improve student's competitiveness.

Thus, global economic and social changes necessitate the formation of students' understanding of professional literature 
in a foreign language, development of skills of adequate translation of professional terminology, written and direct professional communication in a foreign language in order to become future specialists during professional training. Therefore, this problem requires in-depth study.

\section{MATERIALS AND METHODS}

The study was conducted in several stages. At the preparatory stage of the experimental study, we determined its duration, developed a plan and specified the methodology of the pedagogical experiment.

The summative assessment (2016 - 2019) was aimed at determining the state of the problem and was conducted as follows.

1. The first stage involved literature review on the researched problem. At this stage, we studied psychological and pedagogical, methodological, psychological literature, and carried out the analysis of the regulations, namely: the Law of Ukraine "On Higher Education"; Pan-European Recommendations for Language Education: Study, Teaching, Assessment; curricula and working programs for Foreign Language (for professional purposes).

2. The second stage involved a survey of 345 students of 1 st - 4th years of study majoring in 121: Software Engineering, specialized at Software Engineering of Computer Systems, and majoring in Software Engineering of Multimedia and Information Retrieval Systems of National Technical University of Ukraine "Igor Sikorsky Kyiv Polytechnic Institute." The survey was intended to determine the main types of tasks that are of interest and effective in the chosen profession. We conducted the input testing of first-year students to determine their initial level of foreign language proficiency by conducting modular tests. Final testing after the fourth year of studies intended to determine the level of acquired knowledge of a foreign language.

3. We carried out the analysis of methodical provision of teaching foreign language at National Technical University of Ukraine "Igor Sikorsky Kyiv Polytechnic Institute". This analysis confirmed the urgency of our research.

4. Introduction of innovative technologies of teaching English language, analysis of positive and negative dynamics of their application in the learning process.

Statistical analysis software package Statistica was used for quantitative data analysis.

Based on the study [9], a closed-ended questionnaire with scale answers for respondents was developed. Before the survey was used for practical purposes, it was tested on a number of formal criteria - reliability and validity. Ethical criteria such as integrity, truthfulness, competence, respect, and self-identity were also put forward to the questionnaire.

The next step was to determine the tools for measuring the levels of formation of criteria for success and motivation to learn, the main types of educational activities in practical classes in a foreign language.

During the study, the following diagnostic tools were used (research methods):

- study and analysis of modern psychological-pedagogical and scientific-pedagogical literature, normative-legal and organizational documents, reference literature on the research topic;

- questionnaires of students;

- analysis of student performance;

- analysis of the obtained results using the methods of mathematical statistics.

The main limitations of the study were the number and affiliation of respondents to one free economic zone. But the specified number of students and the sample allows to obtain generalized results of the average Ukrainian free economic zone. The findings of the study can be extended to other free economic zones, as the problems considered in the study are typical for all free economic zones of Ukraine.

\section{RESULTS}

Orientation on professional training of the future IT specialist and improving his level of readiness to use a foreign language in professional activity requires development and introduction of innovative teaching technologies which should encourage educational and cognitive activity of students, promote development of independence in acquiring knowledge. Nowadays, this requires a learning technology in which English lessons are supported by enhancing students' cognitive activity, involving active teaching methods (discussions, didactic games, situation modelling).

Since the development of society is associated with the creation of better means of organizing human labour and education, these effective means are usu-ally defined by the term "technology". We state that innovative pedagogical technologies become increasingly important. They aim at improving the professional activity of teachers, developing cognitive activity of students, and in the future implementing the success and effectiveness of the educational process in HEIs [10].

Describing the definition of "learning technology", modern scholars described the ambiguity of its content, and noted that these are effective, practically-proven tools, techniques and methods of joint activities of students and teachers $[10,11]$.

Literature review allowed us to note that innovative technologies in education are information and communication technologies of computer-based learning. The structure, content of educational software, organization of web-space are important when using innovative technologies of teaching English. Thus, based on the Literature review, we can conclude that the Internet is an educational technology that realizes the opportunity for interaction, creating appropriate conditions for successful communication between future specialists and teachers.

Due to the fact that the main objective of learning a foreign language in HEIs is the formation and development of communication skills of future specialists, it becomes important to acquire a practical knowledge of a foreign 
language. There-fore, during the English lesson with the help of the Internet, the formation of reading skills is carried out, using information from the Internet; to improve stu-dents' writing skills; increase vocabulary; to form motivation to learn English.

Due to the fact that the main objective of learning a foreign language in HEIs is the formation and development of communication skills of future specialists, it becomes important to acquire practical foreign language skills. Therefore, information from the Internet is used during the English language lesson in order to improve communication skills in written speech; enlarge vocabulary; form positive motivation to learn English.

Nowadays, there are cases when students in HEIs do not have the motivation to learn a foreign language, and consider it unnecessary for future professional activities. So, it is necessary to introduce new approaches to language teaching. Scholars [12] note that the teaching process is complex and is primarily influenced by practical activities. Students who actively participate in the proposed media activities are important for the socio-cultural context in the academic environment, with a view to their professional development.

In addition, the Internet is a large-scale resource for the teacher, which he can use in preparation for the lesson, the introduction of new types of speech activities [9]. Since the Internet is characterized as an information system, we note that it offers its users a large volume of information and resources. When describing the Internet, it is necessary to emphasize that it includes a set of such services as e-mail, video conferencing, the ability to publish the research papers on different websites for further feedback from different foreign representatives. It allows creating your home page and posting it on the Webserver, provides access to information resources (InfoSeek/UltraSmart, LookSmart, Galaxy) and search engines (Alta Vista, Open Text, WebCrawler) [11].

High school currently provides for a large number of webbased educational tools. So, students have the opportunity to write electronic letters; participate in forums, where they share information and experience, use chats, as well as blogs, social networks, communicate live. All this allows acquiring professional knowledge and skills in order to ensure activity, independence, and develop the ability to cooperate [12].

Today, the rapid development of information and communication technologies, unimpeded access to the Internet provides for the creation of software that allows the use of interactive tools in the educational process of high school.

An innovation of e-learning is the creation of a platform of modular object-oriented dynamic learning environment (MOODLE), which helps teachers to create interactive courses for students according to an optimally organized modular system. The Pearson platform (Dinternal-Books, Pearson) helped to develop language courses for different specialities according to different levels of knowledge of a foreign language.

The researcher [13] classifies online tools for teaching language (OTLT) ac-cording to the following structure: learning/content management system (Moodle), communication tools (Skype), for live or virtual communication (Livestream), social networks (MySpace), blogs, presentation tools (Slides), re-source sharing tools (Google Docs), website creation (Google Sites), web search engines that search for information and learning materials (Google), dictionaries (Merriam Webster Online).

Pearson is an international leader in the provision of educational services, the company developed the Global English Scale, which measures the level of language proficiency. Learning a foreign language, testing and consolidating practical and grammatical skills are realized through Internet technologies.

Today, higher education needs to be organized in combination with the use of innovative technologies for teaching English, using multimedia tools and learning technologies. Therefore, new educational trends should be implemented under the guidance of a competent teacher who has the opportunity to combine language teaching, using new methods and forms of learning. The teacher can use technical means and technologies during the lesson, which helps to improve the teacher's abilities and makes the lessons more interesting and informative. For example, a matrix presentation of the material is realized on the basis of multi-media projectors. Therefore, the emergence of modern teaching methods involving multimedia technologies improves and enriches the learning process, allows processing and assimilating a much larger volume of educational material and, accordingly, increases the practical level of English language proficiency [14].

In his research, foreign scholar [15] notes that today there are changes in digital technologies that are of great importance in the educational process. Students' use of digital technology tools promotes confidence in communicating in a foreign language. Using all these media gadgets, communication is carried out in a natural environment, which contributes to a positive climate in the class and students' interest in learning.

Besides, the teacher, using information and communication technologies in his practice, contributes to the formation of students' autonomy, and socializes the educational process at high school, allowing to make its result the work of many stakeholders. He creates collective creative work not only for one group of students but also for other educational institutions located in different cities and countries. Thus, the use of Internet technology in practical classes helps to optimize learning activities. Today, students can take an active part in on-line conferences (electronic projection of conferences, which is characterized by means of oral speech), which have been actively implemented in HEIs.

The use of modern information and communication technologies during educational activities in educational institutions together with the creation and implementation of new methods of teaching a foreign language allows obtaining a large volume of information, while taking into account 
personal and professional qualities, knowledge and skills of students. For example, $[16,17]$ note that in order to obtain quality education with minimal time and energy, effort of teachers and students, it is necessary to use information and communication technologies in the training of future specialists.

Recently, it has become very popular to use Skype conferences with students and teachers from other countries, held in English, which create authentic conditions for communication, help to remove the language barrier, encourage the use of language.

The use of Skype in the educational process helps to create appropriate conditions for real communication of students in English, promotes the formation of communicative competence.

Today the focus of higher education is the student, his personality, and his in-ner world. Therefore, the main goal of a teacher of HEI is to choose the appropriate innovative teaching technologies for learning English.

Such innovative teaching technologies as video games, which are a unique opportunity to provide knowledge about the real world through an interactive immersion in the virtual world, have also been actively used. With the help of games, you can turn standard language lessons into enjoyable activities that students will enjoy attending. The following video games can be used in practical foreign language classes: Influent, 21 Days, and others.

Researchers [18] tested the English language vocabulary (English as a Second Language, ESL) using SIM 3 video games.

Analysing the studies of other foreign scholars, we noted that [19] developed and designed video games to learn a foreign language, using already known video games (SIM 3, SHAIEx) Other researchers [20] studied digital a game of the Adaptive Hypermedia system, and [21]-[23] used the virtual $3 \mathrm{D}$ world to learn the language.

There are two ways to evaluate a sample. First, by choosing the maximum value of their product. Second, by assessment in the pilot study process. In the first case, you can see that the scope of the product pq lies in the interval:

$$
0,09=0,1 * 0,9 \leq \mathrm{pq} \leq 0,5 * 0,5=0,25
$$

It is this circumstance allows for a rough estimate of $n$ to take $\mathrm{p}=\mathrm{q}=0.5$. Therefore, we can use the value $\mathrm{pq}=\mathrm{p}(1-\mathrm{p})$ $=0.25$.

In the second case, these shares can be taken from aerobatic studies involving 5 institutes $(\mathrm{n} 5 \leq \mathrm{N})$, the results of which are given in Table 1. Taking the number of respondents and the number of answers chosen by them, we obtain $\mathrm{p} 1$ and $\mathrm{q} 1$ for the first answer to the first question $\mathrm{x} 1$.

p1 is the total share of the election answer to the first question For all respondents in the sample, ie the share of dividing the number of elections by the number of questionnaires. In our case $\mathrm{p} 1=86 / 181=0.48$. Accordingly, $\mathrm{q} 1=1-\mathrm{p} 1=1-0.48=0.52$. As mentioned above, their product:

$$
\mathrm{p}_{1} \mathrm{q}_{1}=0,48 * 0,52=0,2496 \cdot 0,25
$$

Confirming the validity of the use of the value of $p=0.5$ in the previous case.

\begin{tabular}{|c|c|c|c|c|c|c|}
\hline Indexes & $\begin{array}{l}\stackrel{8}{0} \\
\Xi \\
0 \\
0\end{array}$ & $\begin{array}{l}\ddot{\infty} \\
\stackrel{0}{\Xi} \\
0 \\
\text { N }\end{array}$ & 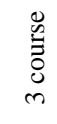 & $\begin{array}{l}\dot{0} \\
\vdots \\
\Xi \\
\delta \\
\forall\end{array}$ & Magistracy & $\Sigma$ \\
\hline $\mathrm{j}$ & 1 & 2 & 3 & 4 & 5 & \\
\hline interviewed & 38 & 31 & 35 & 35 & 42 & 181 \\
\hline $\mathrm{x}_{1}$ & 10 & 10 & 9 & 8 & 10 & 47 \\
\hline $\mathrm{x}_{2}$ & 20 & 15 & 12 & 17 & 22 & 86 \\
\hline$\ldots$ & $\ldots$ & $\ldots$ & $\ldots$ & $\ldots$ & $\ldots$ & $\ldots$ \\
\hline $\mathrm{X}_{15}$ & 15 & 9 & 8 & 8 & 8 & 48 \\
\hline$\Sigma$ & 120 & 103 & 90 & 85 & 122 & 522 \\
\hline
\end{tabular}

Table 1. The results of previous studies

You can also evaluate:

$$
\mathrm{p}_{2} \mathrm{q}_{2}=(47 / 181) *(134 / 181)=0,26 * 0,74 \approx 0,19
$$

for the second line, etc. Then you can take their average value and substitute in formula (1). We use the approximate value of $\mathrm{pq} \approx 0.25$. Substituting the values of $\mathrm{Z}^{2}, \mathrm{PQ}$ and $\mathrm{N}$ in Formula (1) and setting the marginal error of the unique random sample $\Delta$, which characterizes the deviation of the sample mean from the average of the general population equal to 0.05 , ie equal to $5 \%$, we estimate $\mathrm{N}$ :

$$
\mathrm{n}=\left(\mathrm{Z}^{2} \mathrm{pqN}\right) /\left(\Delta^{2} \mathrm{~N}+\mathrm{Z}^{2} \mathrm{pq}\right)=(3,84 * 0,48 * 0,52) *
$$

$5525 /[(0,05 * 5525)+(3,84 * 0,48 * 0,52)]=0,96 * 5525 /$

$(0,0025 * 5525+0,96)=3132 /(8,16+0,96)=3132 / 9,12 \approx$ 343.

Thus, the size of the representative sample must be at least 345 respondents.

There are training programs based on the best examples of world literature, which shape the behaviour of future specialists through imitation and repetition of the actions of literary heroes, and programs that aim at developing the necessary practical skills and family life skills in the future. For example, in the United States, the course The Art of Loving includes 40 literary works, which are divided into three topics: first love and disappointment; romantic relationships; devotion, and marriage. The acquaintance with literary works is followed by their discussion, development of assignments, role-playing games, drawing, and musical improvisation, which stimulates interest in new knowledge and improves the level of training of future specialists [24].

Thus, after analysing the scientific literature, the next step was to conduct a summative assessment, which involved 255 students (of the 1st - 4th years of study) majoring in 121: Software Engineering, specialized at Software Engineering of Computer Systems, and majoring in Software Engineering of Multimedia and Information Retrieval Systems of National Technical University of Ukraine "Igor Sikorsky Kyiv Polytechnic Institute." We studied the following indicators in students:

1. performance (as a result of specially conducted preliminary testing and modular control):

1st year: $18 \%$ - excellent, $27 \%$ - good, $35 \%-$ satisfactory, $20 \%$ - unsatisfactory;

2nd year: $18 \%$ - excellent, 29\% - good, $35 \%-$ 
satisfactory, $18 \%$ - unsatisfactory;

3rd year: $22 \%$ - excellent, $25 \%$ - good, $43 \%$ satisfactory, $10 \%$ - unsatisfactory;

4th year: $22 \%$ - excellent, 27\% - good, 34\% satisfactory, $17 \%$ - unsatisfactory;

2. motivation (results obtained according to questionnaires):

1st year: $17 \%$ - high level, $50 \%$ - medium, 33\% - low;

2nd year: $22 \%$ - high, $52 \%$ - medium, $26 \%$ - low;

3rd year: $22 \%$ - high, $54 \%$ - medium, $18 \%$ - low;

4th year: $25 \%$ - high, $53 \%$ - medium, 22\% - low.

Analysis of the results of the summative stage of the research according to the indicators of academic performance and motivation to learning, the main types of educational activities in practical foreign language classes, generalization of students' requests as regards the purpose of learning a foreign language, the ratio of the requests, and the level of satisfaction of students' needs, showed the following trends.

1. When entering technical HEIs, a large number of students do not have a sufficient level of knowledge of a foreign language, as evidenced by the following data: $34 \%$ satisfactory, $19 \%$ — unsatisfactory, except for pupils who graduated from schools with in-depth study of foreign languages, or pupils who visited the United States and the United Kingdom under exchange programs. In addition, according to the study, students with a high level of foreign language may have low results at the end of the course, and students with a low level may become excellent and have high academic performance. Therefore, the teachers' selection of appropriate innovative teaching technologies allows them to successfully and effectively implement educational activities, as proved by our study.

Analysing the educational process at National Technical University of Ukraine "Igor Sikorsky Kyiv Polytechnic Institute" at the Faculty of Computer Systems Software Engineering, we noted that reproductive teaching methods still dominate in foreign language classes: translation, text rendering, memorization of ready dialogues, which results in disinterest in the study of certain topics.

During the summative assessment, we obtained data on the necessary and real levels of foreign language proficiency of future IT specialists studying at the Faculty of Computer Systems Software Engineering.

As you know, academic performance is only one side of the training of future specialists, and therefore, it does not always adequately demonstrate the true level of knowledge of English. Special professional knowledge and skills only are not enough to ensure the professional readiness of future IT specialists to the conditions of free job search in the modern labour market, and so on.

Analysing the process of development of professional qualities in future IT specialists, we asked students to answer the questionnaire (in the form of incomplete sentences):

1. Practical foreign language classes will be interesting and effective if ...
2. In foreign language classes I like the most when ...

3. An IT specialist is a person who ...

4. To become a professional nowadays you need ...

5. What approaches, methods, forms and technologies of teaching you know that would help to improve the level of knowledge of a foreign language if ...

6. Achieved level of knowledge of a foreign language for future successful professional activity... (insufficient / partially sufficient / sufficient).

7. When learning foreign languages, you should not ...

8. I will need the acquired knowledge of a foreign language in...

9. Attending a foreign language class I get....

Analysing student's responses to the first, second and seventh questions of the questionnaire, were obtained requests to improve the work of a teacher who con-ducts practical foreign language classes: use more communicative exercises; conduct business and role-playing games to develop communication skills; ar-range meetings with native speakers. Table 2 presents the results of the study.

Table. 2. Students' requests expressed in the survey (\%)

\begin{tabular}{cc}
\hline Questions & $\%$ \\
\hline Communicative exercises & 25.0 \\
Discussion & 13.3 \\
Meetings with native speakers & 22.3 \\
Business, role-playing games & 29.8 \\
Allowing for the level of knowledge of students & 27.0 \\
\hline
\end{tabular}

Conducting surveys among students, writing creative works, conducting inter-views found that although some students of technical specialties link their future professional activities with knowledge of a foreign language, only $10 \%$ of students are engaged in self-education using authentic professional sources: foreign language publications, TV shows, Internet, etc.

At the end of the experiment, we re-surveyed students of the experimental (EG) and control (CG) groups. Thus, extracting data for EG and CG from the first questionnaire, and adding data after experiment we received the following indicators: before the experiment there were only $8 \%$ of EG students with high scores, and $8.3 \%$ of surveyed CG students indicated professional need for this course. At the end of the experiment, these data were as follows: $\mathrm{EG}-24.0 \%, \mathrm{CG}-16.7 \%$.

In addition, the study selected ten motives that were most common in students' responses and rated them on a 10-point scale, where we attributed the first rank to the motif with the greatest impact, and the tenth — with the least impact. According to the results of the study, the results of the survey before the experiment did not differ much, so they were combined into one column. Table 3 presents survey data.

Table.3. Motives for learning a foreign language in EG and CG before and

\begin{tabular}{|c|c|c|c|}
\hline \multirow[t]{2}{*}{ Motives } & \multirow{2}{*}{$\begin{array}{l}\text { Before the } \\
\text { experiment } \\
\text { EG and CG }\end{array}$} & \multicolumn{2}{|c|}{$\begin{array}{c}\text { After the } \\
\text { experiment }\end{array}$} \\
\hline & & EG & CG \\
\hline Internship abroad & 4 & 3 & 3 \\
\hline
\end{tabular}




$\begin{array}{lccc}\text { Getting a prestigious job } & 3 & 1 & 2 \\ \begin{array}{l}\text { Work on an international project } \\ \begin{array}{l}\text { Understanding of professional } \\ \text { foreign literature }\end{array}\end{array} & 10 & 7 & 9 \\ \begin{array}{l}\text { Work in an international } \\ \text { company }\end{array} & 4 & 8 & 6 \\ \begin{array}{l}\text { Travel abroad } \\ \begin{array}{l}\text { Learning a foreign language only } \\ \text { because the curriculum requires }\end{array}\end{array} & 9 & 2 & 1 \\ \begin{array}{l}\text { Obtaining a bachelor's/master's } \\ \text { degree abroad }\end{array} & 5 & 5 & 5 \\ \begin{array}{l}\text { Communication with people } \\ \text { from different countries }\end{array} & 8 & 10 & 10 \\ \begin{array}{l}\text { Understanding the content of } \\ \text { movies, songs, magazines, books } \\ \text { in a foreign language }\end{array} & 1 & 4 & 7 \\ \end{array}$

The change in priorities was also explained by the psychological peculiarities of students at different stages of learning. Thus, if in the first year of study the main motives were "communication with people from different countries" and "travel abroad", after the experiment we observed that learning a foreign language to get a prestigious job or work in an international company ranked first in both groups.

Table 3 shows that the main motive for learning a foreign language is working in foreign projects, which indicates the desire of students to integrate into the world educational space. Thus, student encouragement can be based on the formation of communicative competencies.

But it is not only psychological factors that influence motivation to learning. Thus, we explained a fairly high rate of the motive "learning a foreign language only because the curriculum requires" in the CG by the lack of sufficient interest in learning the subject due to the predominance of reproductive teaching methods (rendering, translations of professionally specialized texts). The seventh and ninth ranks of the motives "obtaining a bachelor's/master's degree abroad" and "working on an international project" in CG can be explained only by the inability to practically use the knowledge acquired during foreign language classes in professional activities, lack of practice of holding presentations, participation in role-playing games during classes.

The next stage was the analysis of the results of academic performance in a foreign language (criterion "ability to successfully perform professional foreign language activities"), which we investigated using the data of input control, modular tests, complex tests, examination record data for Foreign Language (for professional purposes). As a result, the rating of academic performance in EG and CG distributed as follows (Table 4).

Table. 4. Comparative table of foreign language performance rating (theoretical and practical level) of students of EG and CG after the experiment

\begin{tabular}{lccccc}
\hline \multicolumn{1}{c}{ Scores } & \multicolumn{2}{c}{ EG } & \multicolumn{2}{c}{ CG } \\
\hline National scale & $\begin{array}{c}\text { ECTS } \\
\text { scale }\end{array}$ & Number & $\%$ & Number & $\%$ \\
\hline Excellent & A & 8 & 32.0 & 4 & 16.7 \\
Good & B & 9 & 36.0 & 6 & 25.0 \\
& C & 5 & 20.0 & 4 & 16.7 \\
Satisfactory & D & 2 & 8.0 & 5 & 20.8 \\
\hline
\end{tabular}

\begin{tabular}{lccccc}
\hline & E & 1 & 4.0 & 4 & 16.7 \\
Unsatisfactory & $\mathrm{F}$ & 0 & 0 & 1 & 4.2 \\
Total & & 25 & \multirow{2}{*}{100} & 24 & \multirow{2}{*}{100} \\
& & students & & students & \\
\hline
\end{tabular}

To obtain a statistically significant answer to the question of whether the performance improved as a result of the experiment, we used the $\varphi$-test, i.e. Fisher angular transformation, designed to compare the two samples by the frequency of detection of the effect we dealt with. Since we were interested in the level of academic performance, the "effect" will be considered the students' groups of scores "good" and "excellent", and the lack of effect — "satisfactory" and "un-satisfactory". Fisher's criterion $\varphi^{*}$ evaluates the reliability of the fact that the percentages of the two samples in which the registered effect of interest to us differ. The essence of the Fisher angular transformation is to convert the percentages of the central angle measured in radians.

We formulated two hypotheses in the course of the study:

H0: the proportion of persons who showed the studied effect in EG not greater than in CG;

H1: The proportion of persons who showed the studied effect in EG greater than in CG.

Table. 5. Table for calculating Fisher's criterion $\varphi^{*}$ in comparison to identify

\begin{tabular}{cccccc} 
& & \multicolumn{4}{c}{ differences in EG and CG } \\
\hline \multirow{2}{*}{ Groups } & \multicolumn{2}{c}{ There is an effect } & \multicolumn{2}{c}{ No effect } & Total \\
\cline { 2 - 5 } & number & $\%$ & number & $\%$ & \\
\hline EG & 22 & $88 \%$ & 3 & $12 \%$ & 25 \\
CG & 13 & $58.3 \%$ & 11 & $41.7 \%$ & 24 \\
Total & 35 & & 14 & & 49 \\
\hline
\end{tabular}

Next, we calculated the empirical value of $\varphi^{*}$ by the formula

$\phi^{*}=\left(\phi_{1}-\phi_{2}\right) \sqrt{\frac{n_{1} n_{2}}{n_{1}+n_{2}}}$

where $\phi_{1}-$ an angle corresponding to a higher percentage $(88 \%)$;

$\phi_{2}-$ an angle corresponding to a lower percentage (58.3\%);

$n_{1}$ - the number of observations in the sample 1 (25);

$n_{2}$ - the number of observations in the sample 2 (24).

$\phi_{1}(88 \%)=2.434$;

$\phi_{2}(58,3 \%)=1.738$.

According to formula (1), we obtained $\varphi^{*}=2.43$.

There are known critical values of $\phi^{*}$ that correspond to certain levels of statistical significance:

$\phi_{c r}^{*}=\left\{\begin{array}{l}1.64(p \leq 0.05) \\ 2.31(p \leq 0.01)\end{array}\right.$

The obtained value of $\phi_{-}$emp $>\phi_{\_}$cr, and indicates a denial of the hypothesis $\mathrm{H} \_0$ and admitting $\mathrm{H} \_1$.

The research evaluated the ability of students to clearly and logically express their opinions, persuade, argue their decisions, lead discussions on professional topics, prepare and conduct presentations during classes and at interdisciplinary 
conferences.

Let us provide the results of a study conducted in the form of a questionnaire involving 345 students of 1 st -4 th years of study majoring in 121: Software Engineering, specialized at Software Engineering of Computer Systems, and majoring in Software Engineering of Multimedia and Information Retrieval Systems at the summative stage of the experiment for more detailed analysis of students' attitudes to a foreign language. We asked students to evaluate some qualitative features of this subject according to the following criteria (from zero to five points):

the importance of this subject;

the student's interest in studying this subject;

clarity of presentation of the material;

the effectiveness of the organization of practical classes;

the effectiveness of the organization of control and evaluation activities.

As a result, we obtained the following indicators: $23 \%$ of the first-year students evaluated the professional significance of this subject by the highest scores (4-5 points), $27 \%$ of the second-year students, $39 \%$ of the third-year students, $52 \%$ of the fourth-year students; interest in this subject: the first-year students $-55 \%$, the second-year students $-70 \%$, the thirdyear students $-60 \%$, the fourth-year students $-64 \%$. These data indicate the need to study this subject in order to improve the quality of professional training.

Conducting discussions, conversations, role-playing games, brainstorming and other creative and interactive methods of general orientation in the first year of study, in the secondfourth - of professional orientation significantly increased the levels of readiness on the criterion of "ability to successfully perform foreign-language professional activities." Activation of the role position of both teachers and students, modelling of communicative and problematic situations in compliance with the principles of differentiation, professional orientation, integration, environmental friendliness, and accessibility allowed to quantitatively and qualitatively increase almost all indicators of readiness, which accordingly affected the use of a foreign language in the professional activities of future IT specialists.

\section{DISCUSSION}

The study of a foreign language in HEIs should be based on innovative teaching technologies. According to the curricula of Foreign Language for professional purposes, professiograms, requirements of international organizations, IT specialists must be ready for effective foreign-language use in their professional activities. This will help them to communicate with specialists from other countries, prepare speeches and present them publicly, to find and process new text, graphic, audio, and video information of foreign-language documents, analyse them in order to obtain materials for fulfilment of professional tasks, as well as translate foreign-language texts on professional topics to obtain data on significant professional achievements of foreign specialists.
As we know from practical activities, a large number of students, primarily future IT specialists, have a low level of knowledge and practical skills in the realization of this knowledge. Besides, while studying in HEIs, students have internal psychological problems that hinder the development of their foreign language skills (uncertainty in their abilities when learning a foreign language, and there-fore students regard the subject Foreign Language (for professional purposes) as optional and not necessary for their future professional activity [25].

According to [26], reflective practice allows students to realize their emotions, individual needs and develop strategies to regulate thinking. Besides, it is equally important to increase the ability of future specialists to solve problems and promote independent critical thinking. Therefore, in a higher education institution, foreign language teachers are obliged to apply emotional norms of regulation during their educational activities. The key structure is to closely align emotional regulatory practices. For example, Dewey stated that people learn in different ways, not just gain experience, with the help of reflective practice. Thus, reflection is goal-oriented and controlled by the student [27]. The goal may change under the influence of a student's self-esteem, because during their studies they may set different goals, thinking about their achievements and failures. On this basis, it is especially important for foreign language teachers, who have been trained before starting their professional activities, to encourage them not only to understand and comprehend the results of language learning, but also to consider the use of a foreign language in the future [26].

Research shows that foreign language teachers who provide services can benefit from the introduction of various tools for effective learning activities. Reflection can help future specialists to develop their emotional intelligence if they use their feelings as an important component of their reflections. This conclusion is based on the already known study that systemic reflection helps to better understand behaviour, promotes motivation, increases confidence and competence [28].

The development of a teacher is related to his own personal development, and how he behaves in class, how he thinks, feels - all this affects the atmosphere in the student collective. Unfortunately, this practice is rare at different levels of teaching (primary school, secondary school, university) [29], despite the fact that there are different tools of reflection for the development of emotional intelligence of foreign language teachers.

Thus, on the basis of the above, modern teachers need to apply innovative technologies of English language teaching in practical classes in order to train specialists so that they are competitive in the labour market.

According to the curriculum of the subject Foreign Language (for professional purposes), the working curriculum Foreign Language (English) (for professional purposes) for the major 121: Software Engineering, specialization Software 
Engineering of Computer Systems, and the major Software Engineering of Multimedia and Information Retrieval Systems of National Technical University of Ukraine "Igor Sikorsky Kyiv Polytechnic Institute", English language program for professional communication, recommended by the Ministry of Education and Science, Youth and Sports of Ukraine, was aligned with the levels of foreign language proficiency.

We analysed the pan-European recommendations for language education, which include the following levels of language proficiency: A (A1, A2), B (B1, B2) and C (C1, C2). Therefore, in order to adapt them to Ukrainian higher education, six levels of foreign language proficiency were identified (Table 5).

Table. 6. General levels of foreign language proficiency

\begin{tabular}{cll}
\hline $\begin{array}{c}\text { Item } \\
\text { No. }\end{array}$ & \multicolumn{1}{c}{$\begin{array}{c}\text { Levels of foreign } \\
\text { language proficiency }\end{array}$} & \multicolumn{1}{c}{ Characteristics } \\
\hline 1. & C & Proficiency \\
& Advanced User & Advanced \\
2. & B & Upper-intermediate, Vantage \\
& Intermediate \\
3. & A & Pre-Intermediate \\
& Basic User & Beginner / Elementary \\
& Advanced User & \\
& B & \\
& Independent user & \\
& A & \\
& Basic User & \\
\hline
\end{tabular}

Analysing the European Guidelines for Language Education on the levels of foreign language proficiency, educational and professional programs (EPP), English language programs for professional communication, working training pro-grams for future IT specialists, we should note that in connection with Ukraine's accession to European educational space and according to modern requirements of employers to specialists, an IT graduate must have B2 level (independent us-er).

On this basis, it is necessary to structure the course and divide the study of the subject Foreign Language (for professional purposes) at National Technical University of Ukraine "Igor Sikorsky Kyiv Polytechnic Institute" into compulsory (bachelor) and optional courses. The purpose of this course is to master a foreign language at the B2 level. Course duration - four academic years.

We called the first stage of professional training, which is conducted in the 1st year of study an adaptive course. At this stage, teachers contribute to the development and consolidation of knowledge, skills and abilities acquired during schooling.

First of all, teachers help students learn the basics of situational communication in a foreign language, as well as develop basic reading skills. In addition, at the beginning of practical classes it is necessary to identify the initial level of foreign language proficiency through testing, which in turn will allow the teacher to properly organize and conduct practical foreign language classes.

Thus, we found what the teacher needs to add to his course: texts from various fields of professional activity and general topics in the subjects that first-year students study.
Therefore, students were taught the following topics: Higher Education in Ukraine and Abroad; Computer (software and hardware, the importance of the Internet in modern life and for the chosen professional activity).

Teaching for first-year students was implemented with the help of textbooks Headway, A Beginner's Course in English for Young Computer Learners, Cutting Edge and grammar books by such foreign authors Murphy, Martin.

We noticed that at the first stage during the study of the basic course of English students of the major 121: Software Engineering, specialization Software Engineering of Computer Systems involve in the educational activities differently.

In order to master a foreign language, the following pedagogical technologies we used at the first year for IT students:

- situational modelling technology (involvement of students in the game with a didactic purpose);

- information technology (solving applied problems through information processing), which contributed to the development of skills and abilities to search for literature: on the Internet using such browsers as Internet Explorer, Mozilla Firefox and various search engines (Meta, Google, Yandex, Lycos). com); for automatic translation of texts using translator applications (PROMT XT); for working out and reproduction of graphics, sound (Microsoft Media Player, Win-Amp, Apollo, WinDVD, zplayer, programs for viewing of images ACD See, PhotoShop, CorelDraw).

In addition, students had the opportunity to hold an open day in English to consolidate knowledge of the topic Higher Education at National Technical University of Ukraine "Igor Sikorsky Kyiv Polytechnic Institute". During this event, students shared their impressions of the first year of study at the university with applicants. Applicants and their parents asked questions, while university staff and students provided detailed information about the educational institution based on the knowledge and experience already gained.

As we know, learning should be interesting, vivid, emotional and figurative, so a method of brainstorming was applied in English classes. At one of the classes on the topic Student Life. Exchange of Students, future IT specialists received the assignment: "A group of students from America would like to visit the university. Think about what souvenirs you will give them, taking into account their customs, what cultural program you will offer." This method promotes the development of thinking, creativity and imagination, which is important for the professional development of future IT specialists. In addition, the brainstorming method teaches students to express their thoughts briefly in English.

The second stage of training was conducted for second-year students, we called it professionally-oriented. Students begin to develop integrated skills to work with professional foreign literature and enlarge vocabulary. Teachers used professionally-oriented texts and articles in practical classes. Besides, the following creative assignments were proposed: "The programmer's role in the mod-ern world", "Profession of 
the future", "Ideal automated place of IT specialist". In addition, discussions on topics related to the future profession were held in pairs and groups. For example, a discussion on the topic: The Importance of English for IT specialists.

The business game technology was also widely used, which contributed to the activation of thinking, the development of independence of future specialists, the formation of creativity, approach to the realities of life. Here is one of the games that was held in one of the classes: Students are divided into two groups. The first is business partners from Ukraine, and the second is from America. Partners begin to talk about their country. Teachers asked the following questions about the country: 1. What countries does Ukraine border? 2. What is the territory of Ukraine? 3. How many administrative regions are there in Ukraine? 4. What can you say about the landscape, seas, rivers, and lakes in Ukraine? 5. What natural resources can be found in Ukraine? 6. What are the main industrial centers in Ukraine?

Such innovative technologies as on-line conferences were used in English classes. The algorithm of their holding is as follows: determining the topic of the conference, its moderator and terms of holding; the call for reports is announced and a press release of the conference is published, which is sent to other HEIs; at the specified time the presentation and discussion of reports is held; the conference ends. The English teachers also organized Skype conferences; friendfeed conferences/seminars; wiki-conferences/seminars; integrated conferences. In order to better learn the material, the teachers also used interactive videos, having informed future IT specialists about the peculiarities of organizing work with them in the process of learning a foreign language in advance. At the end of the course, in order to consolidate the knowledge acquired by the students and check the information, the teacher conducted a computer test and used other developed assignment in electronic form and in the form of presentations.

The third stage of training was implemented for third- and fourth-year students, and was called "professionally-oriented course". In the process of con-ducting practical classes on the subject Foreign Language (for professional purposes), the theme changes according to the professionalization of productive knowledge, integrated skills and abilities: in the learning process the main this is professionally-oriented texts, which help students to prepare for foreign-language communication on professional topics. According to our proposed foreign language curriculum, the following topics were studied: Computer Architecture, Desktop Publishing (DTP), Graphical User Interfaces, Applications Pro-grams. Instructions and Complex Instructions, Multimedia. At this stage, motivation is profiling, because students begin to study specialized subjects that help the student better understand the chosen profession.

The teacher's creative approach is manifested in the forms and types of assignments, the way of providing information, checking the material learnt by the student. For example, having learnt the topic Studying IT, it was proposed to pre- pare an interview with an IT student, who should explain in detail where and how to get the appropriate education, what subjects are studied, what is the subject of their consideration.

Quasi-professional activity (business game technology, case study technology; integrated pedagogical technology) becomes important during the study of the professionally-oriented course, which identifies related components (problems, plots) in different subjects, and combines them into a whole with a given purpose.

In addition, students used computers and Internet resources in English classes. The use of World Wide Web sites contributed to the development of intercultural competence. For example, using the City Net website (http://www.city.net/) al-lowed virtual travel to different countries, which helped to acquaint students with the culture and sights of foreign countries.

Various media websites in English were used in the practical classes: THE WASHINGTON POST (http://www.washingtonpost.com/) CNN World News (http://cnn.com/world), ABC News (http: // www. abcnews.go.com/index.html), BBC World Service (http://www.bbc.co.uk/worldservice). These websites gave students had the opportunity to read articles, listen to news in English.

Educational websites were used in order to develop intercultural competence, for example: Livemocha is a website that offers various language exercises and courses, after which native speakers check the knowledge.

Online tests were also used, which helped to check the student's level of knowledge of grammatical or lexical material.

The content of educational activities in the third stage contributes to the deepening of students' knowledge on the basis of professionally-oriented topics while getting acquainted with the authentic materials of textbooks from original English and American sources. An important feature at this stage is the high informative-ness, integration of course knowledge with related knowledge of professional subjects, support of the necessary theoretical knowledge by methodological developments and manuals with differentiated exercises for students with different levels of knowledge [30].

Bihych in his work [31] insists on the importance of using podcasts in learning a foreign language, which is confirmed by the results of Table 3 and shows the desire of students to develop communicative competencies. Although authors [28] note the importance of forming metacognition through disciplinary discussions, research has shown that students mostly want to acquire general communicative competencies. The study [15] shows the importance of using purely innovative foreign language learning technologies, but the results of the analysis of the obtained data indicate the need to combine innovative methods with traditional ones.

At the same time, the professional competence of modern IT specialists de-pends on the level of their self-organization, self-control, self-assessment, ability to fulfil non-standard tasks 
and implement effective communication [31].

In addition, methods of overcoming obstacles, communicative attack, delegation, reliance on students' life experiences, creating a sense of success in learning, etc. were also effective in increasing students' motivation.

All the above innovative learning technologies were actively implemented in the educational process in the teaching of the subject Foreign Language (for professional purposes) for future IT specialists as part of their professional training. We noted that their introduction into the educational process was positive for improving the level of foreign language proficiency.

\section{CONCLUSION}

The use of innovative technologies for teaching English to future IT specialists allowed improving the quality of education, developing creativity in students, as well as teaching them to think independently and work with educational material.

It should be emphasized that the incorporation of innovative technologies for teaching English in the educational process should be based on their pedagogically sound combination with traditional methodological systems of teaching and with mandatory justification of pedagogical reasonability of such use, i.e. education should meet new needs of the society.

Thus, the information-rich educational process in combination with the use of innovative technologies, wellorganized e-learning, interactive training courses, multimedia tools improves the program of teaching and learning foreign languages in general, and English in particular, increases the level of knowledge of future IT specialists, and motivation to learn foreign languages, allows students to use a variety of authentic materials. We state that all these factors influence the process of individualization of learning and contribute to the successful mastery of a foreign language.

In our opinion, the materials presented in the article show that one of the most important strategic tasks at the current stage of modernization of higher education in Ukraine is to provide quality professional training at the level of international standards. The solution of this problem is possible under the condition of change of pedagogical methods and introduction of innovative technologies of teaching.

Innovative technologies that increase the educational and cognitive activities of students and increase the level of their knowledge are such information and communication technologies as MOODLE (Modular Object-Oriented Dynamic Learning Environment), business game, integrated pedagogical technology, case study technology have become important in our time in teaching a foreign language in higher educational institutions. Although their important role in shaping the level of foreign language proficiency in future professional activities is identified, further research is needed to create appropriate psychological and pedagogical conditions for the effective use of these technologies in foreign language learning in training future IT specialists. In addition, it is necessary to develop a logically structured structural model of the educational process, which aims at increasing the level of foreign language proficiency in order to actively use it in future professional activities.

\section{ACKNOWLEDGMENT}

We express our sincere gratitude to all students of National Technical University of Ukraine "Igor Sikorsky Kyiv Polytechnic Institute" majoring in 121: Soft-ware Engineering, specialized at Software Engineering of Computer Systems, and majoring in Software Engineering of Multimedia and Information Retrieval Systems, as well as fellow teachers who assisted in the study.

\section{References}

[1] S. Muthuraman, "Quality of blended learning education in higher education," The Online Journal of Distance Education and e-learning, vol. 6, no. 4, 48-56, 2018.

[2] A. S. Canagarajah, "Translingual practice: global Englishes and cosmopolitan relations." New York: Routledge, 2013.

[3] H. Jarvis and M. Achilleos, "From computer assisted language learning (CALL) to mobile assisted language use (MALU)," TESL-EJ, vol. 16, no. 4, March 2013. Available: https://files.eric.ed.gov/fulltext/EJ1004355.pdf

[4] H. Kotina, M. Stepura, V. Fedosov, D. Hrysohlazov and M. Bilinets, "Competitiveness of Higher Education in Ukraine and Certain European Countries: Empirical Studies on Funding and Academic Attractiveness," WSEAS Transactions on Business and Economics, vol. 17, pp. $849-858, \quad 2020$. https://doi.org/10.37394/23207.2020.17.83

[5] A. Sun and X. Chen, "Online education and its effective practice: A research review," J Inf Tech Educ: Res, vol. 15, 2016.2 Available: http://www.jite.org/documents/Vol15/JITEv15ResearchP1 57-190Sun2138.pdf.

[6] J. Trespalacios and J. Rand, "Using asynchronous activities to promote sense of community and learning in an online course," Int J Online Pedag Cours Design, vol. 5, no. 4, 2015. Available: ScholarWorks, https://scholarworks.boisestate.edu/edtech_facpubs/129/.

[7] L. C. Lee and K. C. Hao, "Designing and evaluating digital game-based learning with the ARCS motivation model, humor, and animation," Int J Techn Hum Interact, vol. 11, no. 2, p. 80, April 2015. Available: ResearchGate, https://www.researchgate.net/publication/281894255_Des igning_and_Evaluating_Digital_Game-

Based_Learning_with_the_ARCS_Motivation_Model_Hu mor_and_Animation

[8] S. Guri-Rosenblit, "E-Teaching in higher education: An essential prerequisite for eLearning," Journal of New Approaches in Educational Research, vol. 7, no. 2, pp. 93-97, 2018. https://doi.org/10.7821/naer.2018.7.298.

[9] L. K. Stoll., L. B. Lamont, S. B. Block, and B. J. Esselman, "Redesigned pre-service training for teaching assistants in high enrollment, active learning based 
general chemistry courses", In S. B. Boesdorfer, Ed., Best Practices in Chemistry Teacher Education, ACS Symposium Series; American Chemical Society: Washington, DC, pp. 97-117, 2019. Available: https://pubs.acs.org/doi/abs/10.1021/bk-2019-1335.ch009

[10] M, Goyal, R. Krishnamurthi and D. Yadav, "E-learning Methodologies: Fundamentals, technologies and applications (Computing and Networks)," London: The Institution of Engineering and Technology, 2021.

[11] S. V. Bondar, "The use of Internet technologies in the system of autonomous study of professionally-oriented foreign language by students of non-language specialties," Inf Tech Learn Tools, vol. 34, no. 2, pp. 75-81, 2013.

[12] K. E Johnson and P. R. Golombek, Mindful L2 Teacher Education: A Sociocultural Perspective on Cultivating Teachers' Professional Development (ESL \& Applied Linguistics Professional Series). London and New York: Routledge, 2016.

[13] J. Son, "Online tools for language teaching," TESL-EJ, vol. 15, no. 1, June 2011. Available: http://www.teslej.org/wordpress/issues/volume15/-ej57/ej57int/

[14]N. Yu. Drozdovych, "Using social networks to learn English for technical purposes," presented at $9^{\text {th }}$ International scientific-practical conference "Modern approaches and innovative trends in foreign language teaching", Kyiv, Ukraine, 2014.

[15]Ng. Wan, "New Digital Technology in Education: Conceptualizing Professional Learning for Educators." Dordrecht: Springer, 2015.

[16]D. Persano Adorno, and L. Bellomonte, "Active learning in a real-world bioengineering problem: A pilot-study on ophthalmologic data processing", Computer Applications in Engineering Education, vol. 27, no. 2, pp. 485-499. 2019.

[17] P. V. Sysoyev and M. N. Evstigneev, "The methodology of foreign language teaching using new information and communication Internet-technologies." Moscow: GlossaPress, 2010.

[18] G. Lugaresi, Z. Lin, N. Frigerio, M. Zhang and A. Matta, "Active learning experience in simulation class using a LEGO-based manufacturing system", In 2019 Winter Simulation Conference (WSC), IEEE, pp. 3307-3318. 2019.

[19] C. Julia', and J. O'. Antolı', "Impact of implementing a long-term STEM-based active learning course on students motivation", International Journal of Technology and Design Education, vol. 29, no. 2, pp. 303-327. 2019.

[20] C. Alario-Hoyos, I. Estevez-Ayres, C. D. Kloos, P. J. Muñoz-Merino, E. N. R. I. Q. U. E. LlorentePe'rez and J. Villena-Roman, "Redesigning a freshman engineering course to promote active learning by flipping the classroom through the reuse of MOOCs", International Journal of Engineering Education, vol. 35, no. 1B, pp. 385-396. 2019.

[21] A. Berns, A. G. Pardo, and D. Camacho, "Game-like language learning in 3-D virtual environments," Comput Educ, vol. 60, no. 1, p. 210. Available: ScienceDirect,
https://www.sciencedirect.com/science/article/abs/pii/S03 60131512001601?via\%3Dihub.

[22] M. B. Ibanez, J. J. Garcia, S. Galan, D. Maroto, D. Morillo, and C. D. Kloos, "Design and implementation of 3D multi-user virtual world for language learning," J Educ Techno Soc, vol. 14, no. 4, pp. 2-10, 2011.

[23] A. Mooney, S. Bergin and E. Hegarty Kelly, "Incorporating the Virtual Programming Lab into a First Year Computer Science Module," Available: http://mural.maynoothuniversity.ie/12012/1/Mooney_Tec hnology_Y1CSP_2017.pdf

[24] V. Kravets and S. Kravets, "Pre-marital Youth Training in Modern History: Foreign Experience Ukraine-EuropeWorld," in The International Collection of Scientific Works. Series: History, International Relations, L. M. Alexiyevets, Ed. Ternopil, Ukraine: Publishing House of Ternopil Volodymyr Hnatiuk National Pedagogical University, 2019, pp-123-135.

[25] O. B. Bihych, N. F. Borysko, H. E. Boretska et al., "Methods of teaching foreign languages and cultures: theory and practice," S. Yu. Nikolaieva, Ed. Kyiv: Lenvit, 2013.

[26] I. Zadorozhna, O. Datskiv, and N. Levchyk, "Development of pre-service foreign languages teachers' emotional intelligence by means of reflection," Advanc Educ, no. 10, 2018. Available: http://ae.fl.kpi.ua/article/view/144538/152019.

[27] M. Cardoso, R. Marques, A. V. de Castro and A'. Rocha, "Using Virtual Programming Lab to improve learning programming: The case of Algorithms and Programming," Expert Systems, vol. 38, no. 4, e12531, 2020. https://doi.org/10.1111/exsy.12531

[28] O'Hara S, Pritchard R, and Pitta D. "Teaching with and for metacognition in disciplinary discussions." In N. Feza, Ed., Metacognition in Learning, IntechOpen, 2019. https://doi.org/10.5772/intechopen.86665

[29] A. Barrichello, R. Scabim Morano, P. R. Feldmann and R. R. Jacomossi, "The importance of education in the context of innovation and competitiveness of nations," International Journal of Education Economics and Development (IJEED), vol. 11, no. 2, pp. 201-224, 2020.

[30]M. O. Kyshnirov, "Modern approaches to foreign language teaching: focus on the values of personal development and humanism," Pedag Sci: Theor, Hist, Innov Technol, no. 8, pp. 348-356, 2014.

[31]O. B. Bihych, "Blog and podcast of technology for the formation of intercultural competence at different levels of foreign language learning," Foreign Lang, vol. 3, pp. 3-9, 2017.

\section{Creative Commons Attribution License 4.0 (Attribution 4.0 International, CC BY 4.0)}

This article is published under the terms of the Creative Commons Attribution License 4.0 https://creativecommons.org/licenses/by/4.0/deed.en_US 